\title{
A continuous fluorescent assay for the determination of plasma and tissue angiotensin I-converting enzyme activity
}

M.F. Alves ${ }^{1}$, M.C. Araujo ${ }^{1}$, M.A. Juliano ${ }^{1}$, E.M. Oliveira ${ }^{4}$, J.E. Krieger ${ }^{3}$, D.E. Casarini², L. Juliano ${ }^{1}$ and A.K. Carmona ${ }^{1}$

\begin{abstract}
${ }^{1}$ Departamento de Biofísica, ${ }^{2}$ Disciplina de Nefrologia, Departamento de Medicina, Escola Paulista de Medicina, Universidade Federal de São Paulo, São Paulo, SP, Brasil ${ }^{3}$ Laboratório de Genética e Cardiologia Molecular, Instituto do Coração, Faculdade de Medicina, ${ }^{4}$ Laboratório de Bioquímica da Atividade Motora, Escola de Educação Física e Esporte, Universidade de São Paulo, São Paulo, SP, Brasil
\end{abstract}

\author{
Correspondence \\ A.K. Carmona \\ Departamento de Biofísica \\ EPM, UNIFESP \\ Rua 3 de Maio, 100 \\ 04044-020 São Paulo, SP \\ Brasil \\ E-mail: adriana@biofis.epm.br \\ Research supported by FAPESP \\ and CNPq.
}

Received September 22, 2004 Accepted April 5, 2005

\begin{abstract}
A continuous assay using internally quenched fluorescent peptides with the general sequence Abz-peptidyl-(Dnp)P-OH (Abz = orthoaminobenzoic acid; Dnp = 2,4-dinitrophenyl) was optimized for the measurement of angiotensin I-converting enzyme (ACE) in human plasma and rat tissues. Abz-FRK(Dnp)P-OH, which was cleaved at the Arg-Lys bond by ACE, was used for the enzyme evaluation in human plasma. Enzymatic activity was monitored by continuous recording of the fluorescence $\left(\lambda_{\mathrm{ex}}=320 \mathrm{~nm}\right.$ and $\left.\lambda_{\mathrm{em}}=420 \mathrm{~nm}\right)$ at $37^{\circ} \mathrm{C}$, in $0.1 \mathrm{M}$ Tris- $\mathrm{HCl}$ buffer, $\mathrm{pH} 7.0$, with $50 \mathrm{mM} \mathrm{NaCl}$ and $10 \mu \mathrm{M} \mathrm{ZnCl}_{2}$. The assays can be performed directly in the cuvette of the fluorimeter and the hydrolysis followed for 5 to $10 \mathrm{~min}$. ACE measurements in the plasma of 80 healthy patients with Hip-His-Leu and with AbzFRK(Dnp)P-OH correlated closely $(r=0.90, \mathrm{P}<0.001)$. The specificity of the assay was demonstrated by the complete inhibition of hydrolysis by $0.5 \mu \mathrm{M}$ lisinopril or captopril. Abz-FRK(Dnp)P-OH cleavage by ACE was monitored in rat lung, kidney, heart, and liver homogenates in the presence of a cocktail of inhibitors containing trans-epoxy-succinyl-L-leucylamido-(4-guanido)-butene, pepstatin, phenyl-methylsulfonyl fluoride, $N$-tosyl-L-phenylalanyl-chloromethyl ketone, and $N$-tosyl-lysyl-chloromethyl ketone to prevent undesirable hydrolysis. ACE activity in lung, heart and kidney homogenates, but not in liver homogenates, was completely abolished by $0.5 \mu \mathrm{M}$ lisinopril or captopril. The advantages of the method are the procedural simplicity and the high sensitivity providing a rapid assay for ACE determinations.
\end{abstract}

\section{Introduction}

Angiotensin-I-converting enzyme (ACE, EC 3.4.15.1) is a dipeptidyl carboxypeptidase whose best-known physiological func-
Key words

- Angiotensin-converting enzyme activity

- Fluorometric assay

- Rat tissue angiotensinconverting enzyme

- Human plasma angiotensin-converting enzyme 
dipeptides (2). ACE is expressed as a somatic isoform (150-180 kDa) in endothelial, epithelial and neuroepithelial cells and as a smaller isoform (90-110 kDa) only in germinal cells in the testes. Somatic ACE is an ectoenzyme attached to the cell membrane composed of two highly homologous domains, $\mathrm{N}$ - and $\mathrm{C}$-domains, each possessing a functional active site $(3,4)$. The germinal form of ACE is also a membrane-bound enzyme which contains a single active site corresponding to the $\mathrm{C}$-domain of the somatic form $(5,6)$. Plasma or soluble ACE is derived from proteolytic shedding from the cell membrane $(7,8)$.

ACE is found in the plasma membrane of vascular endothelial cells, with high levels being present in the lung vascular endothelial surface but the enzyme can be also found in the epithelial cells of renal proximal tubules, in the gastrointestinal tract, in cardiac tissues, and in various regions of the brain $(9,10)$. This wide distribution of the enzyme and its presence in many tissues where other components of the renin-angiotensin system are not present reinforce the idea that ACE probably has other roles in addition to the production of angiotensin II or the inactivation of bradykinin $(11,12)$.

The hydrolysis of synthetic substrates used for assaying ACE activity is detected by spectrophotometric $(13,14)$, fluorometric (15-18), HPLC (19), radiometric (20), and radioimmunoassay (21) methods. However, each of these techniques has its own limitations, such as being very laborious, having low sensitivity, or employing substrates whose products resulting from ACE activity are destroyed by other enzymes, with a consequent underestimate of ACE levels. Therefore, convenient and specific substrates are still required for the determination of ACE activity in biological fluids and tissues.

We have described internally quenched fluorogenic substrates for ACE with blocked (Abz-peptidyl-EDDnp analogues of bradykinin where $\mathrm{Abz}$ is ortho-amino benzoic acid and EDDnp is 2,4-dinitrophenyl ethylenediamine) or free (Abz-peptidyl-K(Dnp)P$\mathrm{OH}) \mathrm{C}$-terminal carboxyl groups $(22,23)$. In the present study, we describe the susceptibility of Abz-peptidyl-K(Dnp)P-OH derivatives to hydrolysis by ACE from purified rabbit lung. We also describe the use of these substrates for ACE activity determinations in human plasma and in crude extracts of rat tissues. These internally quenched fluorogenic substrates provide a very sensitive method for ACE determinations and can be used on a continuous basis even at low ACE concentrations. In addition, since the fluorescence signal appears immediately after hydrolysis, subsequent digestion of the products of ACE activity will not interfere with the enzyme activity measurement.

\section{Material and Methods}

\section{Material}

Captopril, lisinopril, trans-epoxy-succinyl-L-leucylamido-(4-guanido)-butene (E64), phenyl-methylsulfonyl fluoride (PMSF), pepstatin, $N$-tosyl-L-phenylalanyl-chloromethyl ketone (TPCK), $N$-tosyl-lysyl-chloromethyl ketone (TLCK), and ortho-phthaldialdehyde were from Sigma (St. Louis, MO, USA). All other chemicals were of reagent grade.

\section{Peptide synthesis}

Hippuryl-His-Leu (Hip-His-Leu) and His-Leu were synthesized as described $(24,25)$. The internally quenched fluorogenic peptides containing the Dnp group incorporated into the $\varepsilon-\mathrm{NH}_{2}$ of a Lys residue were synthesized by the solid-phase methodology, using Fmoc technology and H-Pro-2chlorotrityl resin (26). All the peptides obtained were purified by semi-preparative HPLC, and the molecular weight and purity were checked by amino acid analysis and by molecular mass determination with MALDI- 
TOF mass spectrometry, using a TofSpec E from Micromass (Manchester, UK). Stock solutions of the fluorogenic peptides were prepared in DMSO and the concentrations were determined using the EDDnp molar extinction coefficient $\varepsilon_{365}=17,300 \mathrm{M}^{-1} \mathrm{~cm}^{-1}$.

\section{Enzymes}

Purified rabbit lung ACE was purchased from Sigma. The molar concentration of the enzyme was determined by active site titration with lisinopril as described (27).

\section{Human plasma samples}

Blood was obtained from healthy donors by arm venipuncture. All subjects gave written informed consent to participate in the study. The protocol was approved by the Ethics Committee on Human Experimentation (Hospital São Paulo, Universidade Federal de São Paulo, São Paulo, SP, Brazil). For the study, heparin-treated blood was centrifuged at $1000 \mathrm{~g}$ for $10 \mathrm{~min}$ and plasma was removed and stored at $-20^{\circ} \mathrm{C}$.

\section{Crude aqueous extracts of rat tissues}

Samples of Wistar rat (200-250 g) lung, kidney, heart, and liver were quickly harvested, rinsed, blotted, and homogenized in Tris- $\mathrm{HCl}$ buffer, $\mathrm{pH} 7.0$, containing $50 \mathrm{mM}$ $\mathrm{NaCl}$. Homogenates were centrifuged at 1000 $g$ for $10 \mathrm{~min}$ and the supernatant was frozen at $-20^{\circ} \mathrm{C}$. The protein contents of the samples were measured by the method of Bradford (28) using bovine serum albumin as standard.

\section{Determination of kinetic parameters for Abz-peptidyl-K(Dnp)P-OH derivatives}

The purified rabbit lung ACE activity on Abz-FRK(Dnp)P-OH derivatives was determined at $37^{\circ} \mathrm{C}$ in $0.1 \mathrm{M}$ Tris- $\mathrm{HCl}$ buffer containing $50 \mathrm{mM} \mathrm{NaCl}$ and $10 \mu \mathrm{M} \mathrm{ZnCl}_{2}$,
$\mathrm{pH} 7.0$ (1.0 ml final volume). Enzymatic activity was continuously monitored with a Hitachi F-2000 (Tokyo, Japan) fluorometer by measuring fluorescence at $\lambda_{\mathrm{ex}}=320 \mathrm{~nm}$ and $\lambda_{\text {em }}=420 \mathrm{~nm}$. The slope was converted into $\mu \mathrm{mol}$ substrate hydrolyzed/minute on the basis of a calibration curve obtained after complete hydrolysis of each peptide. For the determination of the kinetic parameters the enzyme concentration was chosen so as to hydrolyze less than $5 \%$ of the substrate present per unit time in order to obtain the initial rate. To correct for the inner filter effect we used an adjusting equation determined experimentally for 0.1 to $100 \mu \mathrm{M}$ Abz-FR-OH, used as standard for fluorescence measurements (23). The $k_{\text {cat }} / K_{\mathrm{m}}$ values were calculated from the kinetic parameters $k_{\text {cat }}$ and $K_{\mathrm{m}}$ obtained by analysis of the non-linear regression data with the GraFit program (29). The standard deviations of the $k_{\text {cat }}$ and $K_{\mathrm{m}}$ values were less than $7 \%$.

\section{Determination of substrate cleavage site}

The scissile bonds of the hydrolyzed peptides were determined by isolation of the fragments by analytical HPLC, and their structures deduced by amino acid sequencing using a PPSQ-23 protein sequencer (Shimadzu, Tokyo, Japan) and by MALDI-TOF mass spectrometry.

\section{Determination of ACE activity in human plasma}

Measurement of human plasma ACE activity using Hip-His-Leu as substrate was performed by the fluorometric method described by Friedland and Silverstein (15). Briefly, $10 \mu \mathrm{l}$ serum was added to the assay solution containing $5 \mathrm{mM}$ Hip-His-Leu in $0.1 \mathrm{M}$ potassium phosphate buffer, $\mathrm{pH} 8.3$, containing $0.3 \mathrm{M} \mathrm{NaCl}$, at $37^{\circ} \mathrm{C}$, in a final volume of $250 \mu \mathrm{l}$. The product, His-Leu, was quantified by measuring the fluorescent adduct formed with ortho-phthaldialdehyde 
with a Hitachi F-2000 spectrofluorometer $\left(\lambda_{\mathrm{ex}}=360 \mathrm{~nm}\right.$ and $\left.\lambda_{\mathrm{em}}=500 \mathrm{~nm}\right)$. ACE activity is reported as $\mathrm{mU} / \mathrm{ml}$ plasma $(1 \mathrm{mU}$ $=$ nmol of histidyl-leucine formed per minute).

Human plasma ACE activity on AbzFRK(Dnp)P-OH was determined under the optimal experimental conditions (buffer, $\mathrm{pH}$, chloride and zinc ions) previously established for recombinant wild-type ACE (23). Enzymatic activity was continuously monitored with a Hitachi F-2000 fluorometer by measuring the fluorescence $\left(\lambda_{\mathrm{ex}}=320 \mathrm{~nm}\right.$ and $\lambda_{\text {em }}=420 \mathrm{~nm}$ ) for 5-10 min. Before starting the reaction by the addition of the substrate, the plasma was preincubated for 5 min in a thermostated cuvette at $37^{\circ} \mathrm{C}$ in the assay buffer. The sensitivity of the assay was tested with 1-10 $\mu \mathrm{l}$ plasma incubated in a final volume of $1 \mathrm{ml}$. For ACE determination, $5 \mu$ plasma was incubated with $10 \mu \mathrm{M}$ Abz-FRK(Dnp)P-OH at $37^{\circ} \mathrm{C}$ in $0.1 \mathrm{M}$ Tris$\mathrm{HCl}, \mathrm{pH} 7.0$, containing $50 \mathrm{mM} \mathrm{NaCl}$ and 10 $\mu \mathrm{M} \mathrm{ZnCl}{ }_{2}$, in a final volume of $1.0 \mathrm{ml}$. The slope was converted into nmol substrate hydrolyzed per minute based on a calibration curve obtained by complete hydrolysis of the peptide as reported previously (23). ACE activity is reported as $\mathrm{mU} / \mathrm{ml}$ plasma $(1 \mathrm{mU}$ $=$ nmol of Abz-FRK(Dnp)P-OH hydrolyzed per minute). The measurements of ACE activity in the plasma of 80 healthy subjects using Hip-His-Leu and Abz-FRK(Dnp)P$\mathrm{OH}$ as substrates were carried out in duplicate. Data were submitted to regression analysis and the paired Student $t$-test was used for comparison of the means in the correlation study (30).

\section{Determination of ACE activity in rat tissues}

ACE activity in rat tissue extracts was determined using Abz-FRK(Dnp)P-OH derivatives as substrates by continuously measuring the fluorescence in the cuvette (5-10 $\min )$ as described above. The assays were performed at $37^{\circ} \mathrm{C}$ in $0.1 \mathrm{M}$ Tris-HCl buffer,
pH 7.0, containing $50 \mathrm{mM} \mathrm{NaCl}$ and $10 \mu \mathrm{M}$ $\mathrm{ZnCl}_{2}$, in a final volume of $1.0 \mathrm{ml}$. Inhibitors of the hydrolytic activities we wanted to suppress (10 $\mu \mathrm{M}$ E64, $1 \mu \mathrm{M}$ pepstatin, $1 \mathrm{mM}$ PMSF, $100 \mu \mathrm{M}$ TLCK, and $100 \mu \mathrm{M}$ TPCK) were added to the buffer. Before starting the reaction by the addition of $10 \mu \mathrm{M}$ substrate, the tissue homogenates ( 1 to $30 \mu \mathrm{l})$ were preincubated for $5 \mathrm{~min}$ in the assay buffer at $37^{\circ} \mathrm{C}$. ACE activity is reported as $\mathrm{mU} / \mathrm{mg}$ protein $(1 \mathrm{mU}=$ nmol of substrate hydrolyzed per minute). The measurements were performed in duplicate.

\section{Inhibitor studies}

$\mathrm{ACE}$ activity in the presence of the inhibitors was determined using $10 \mu \mathrm{M}$ AbzFRK(Dnp)P-OH as substrate. Lisinopril (0.5 $\mu \mathrm{M})$ or captopril $(0.5 \mu \mathrm{M})$ was preincubated with samples of human plasma or rat tissues for $30 \mathrm{~min}$ at $37^{\circ} \mathrm{C}$ before the addition of the substrate.

\section{Results}

\section{Determination of kinetic parameters for hydrolysis of Abz-peptidyl-K(Dnp)P-OH analogues by purified rabbit lung ACE}

Table 1 shows the kinetic parameters for hydrolysis by purified rabbit lung ACE of the peptide Abz-FRK(Dnp)P-OH and its analogues containing Tyr, Ser and Thr in place of Phe. The results were similar to those previously reported for human recombinant wild-type ACE (23). The highest $k_{\text {cat }} /$ $K_{\mathrm{m}}$ value was observed for Abz-FRK(Dnp)P$\mathrm{OH}$, indicating a preference for $\mathrm{Phe}$ at the $\mathrm{P}_{2}$ position of the substrates. The four peptides were cleaved at the Arg-Lys(Dnp) bond, as determined by HPLC analysis and amino acid sequencing of the reaction products. The Pro residue at the $\mathrm{C}$-terminal makes the substrates more resistant to carboxypeptidases. In addition, it is well known from previous studies with ACE inhibitors that 
Pro in the C-terminal is well accepted by ACE (31). Abz-FRK(Dnp)P-OH, which was cleaved with the highest catalytic efficiency by rabbit lung ACE, was chosen as the reference substrate.

\section{Measurement of ACE in human plasma}

Abz-FRK(Dnp)P-OH was used as substrate to quantify ACE activity in human plasma. Fluorescence appeared after cleavage of the Arg-Lys(Dnp) bond as shown by HPLC analysis and amino acid sequencing of the reaction products. The assay required as little as $1 \mu \mathrm{l}$ plasma in a final volume of $1 \mathrm{ml}$. A linear relationship between the rate of hydrolysis and the volume of human plasma added was observed in the range investigated, 1 to $10 \mu$ (Figure 1). Regression analysis was performed on data for 80 healthy patients using Hip-His-Leu and Abz$\mathrm{FRK}$ (Dnp)P-OH as substrates, as shown in Figure 2. The paired Student $t$-test indicated that the results obtained correlated and were significant $(\mathrm{r}=0.90, \mathrm{P}<0.001)$. The hydrolysis of Abz-FRK(Dnp)P-OH by human plasma was completely inhibited by $0.5 \mu \mathrm{M}$ lisinopril or captopril, demonstrating the specificity of the assay.

\section{ACE activity in rat tissues}

ACE activities in tissue homogenates of rat lung, kidney, heart, and liver were examined using Abz-FRK(Dnp)P-OH as substrate. In these assays, classical inhibitors of cysteine, aspartyl and serine peptidases $(10 \mu \mathrm{M}$ E64, $1 \mu \mathrm{M}$ pepstatin, $1 \mathrm{mM}$ PMSF, $100 \mu \mathrm{M}$ TLCK, and $100 \mu \mathrm{M}$ TPCK) were added to prevent undesirable hydrolysis. Except for the liver extracts, in which the hydrolysis of Abz-FRK(Dnp)P-OH was only partially blocked (58\%), in lung, heart and kidney the cleavage of this substrate was completely abolished by $0.5 \mu \mathrm{M}$ lisinopril or captopril (Table 2). The residual activity in the liver was inhibited by the addition of $1 \mathrm{mM}$ ortho-
Table 1. Kinetic parameters for the hydrolysis of Abz-FRK(Dnp)P-OH and some of its derivatives by purified rabbit lung ACE.

\begin{tabular}{lrrcc}
\hline Substrate & $K_{\mathrm{m}}(\mu \mathrm{M})$ & $k_{\text {cat }}\left(\mathrm{s}^{-1}\right)$ & $k_{\text {cat }} / K_{\mathrm{m}}\left(\mu \mathrm{M}^{-1} \mathrm{~s}^{1}\right)$ & Relative $k_{\text {cat }} / K_{\mathrm{m}}$ \\
\hline Abz-FRK(Dnp)P-OH & 7.9 & 211.2 & 45.4 & $1.0^{*}$ \\
Abz-YRK(Dnp)P-OH & 7.0 & 210.0 & 30.0 & 0.66 \\
Abz-SRK(Dnp)P-OH & 12.6 & 98.2 & 7.8 & 0.17 \\
Abz-TRK(Dnp)P-OH & 6.2 & 16.1 & 2.6 & 0.06
\end{tabular}

Experimental conditions: the assays were performed at $37^{\circ} \mathrm{C}$ in $0.1 \mathrm{M} \mathrm{Tris}-\mathrm{HCl}, \mathrm{pH} 7.0$, containing $50 \mathrm{mM} \mathrm{NaCl}$ and $10 \mu \mathrm{M} \mathrm{ZnCl}$, in a final volume of $1.0 \mathrm{ml}$.

${ }^{*} \mathrm{~A}$ relative $k_{\mathrm{cat}} / K_{\mathrm{m}}$ value of 1.0 was assigned to $\mathrm{Abz}-\mathrm{FRK}(\mathrm{Dnp}) \mathrm{P}-\mathrm{OH}$ which was hydrolyzed with the highest catalytic efficiency. Abz-FRK(Dnp)P-OH $=$ ortho-aminobenzoic acid-FRK-(2,4-dinitrophenyl)P-OH.

Figure 1. Linear relationship between the velocity of hydrolysis of 10 $\mu \mathrm{M}$ Abz-FRK(Dnp)P-OH and the volume of human plasma. In the inset, continuous fluorescence recording of the substrate hydrolysis by plasma: $1 \mu \mathrm{l}$ (circles), 2 $\mu \mathrm{l}$ (squares), $5 \mu \mathrm{l}$ (filled triangles), $10 \mu \mathrm{l}$ (filled inverted triangles), and 10 $\mu \mathrm{l}+0.5 \mu \mathrm{M}$ lisinopril (lozenges). The slope was converted into $\mu \mathrm{mol}$ of substrate hydrolyzed/ min based on a calibration curve obtained from

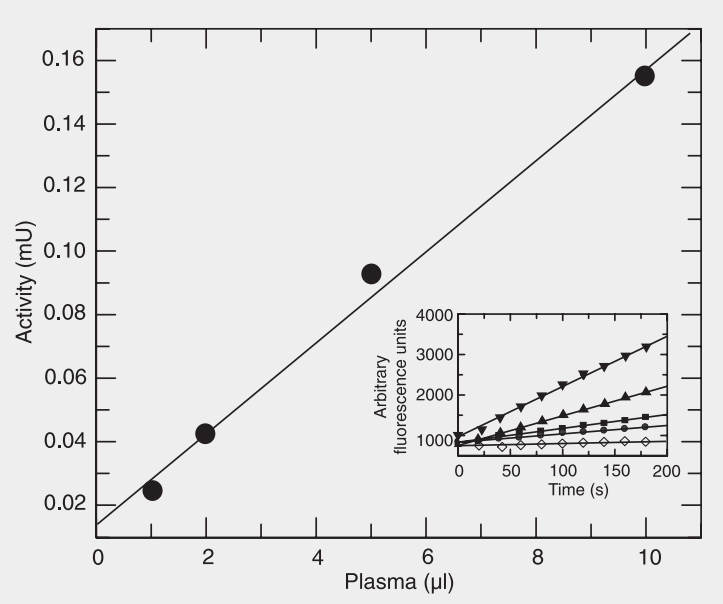

complete hydrolysis of Abz-FRK(Dnp)P-OH (slope $=4600 \mathrm{AFU} / \mu \mathrm{M}$ of Abz-FR). AbzFRK(Dnp)P-OH = ortho-aminobenzoic acid-FRK-(2,4-dinitrophenyl)P-OH. Measurements were made in duplicate and differences were $<5 \%$.

Figure 2. Linear regression analysis of paired data of angiotensin I-converting enzyme activity in plasma from 80 normal patients using Hip-HisLeu (x-axis) and AbzFRK(Dnp)P-OH (y-axis) as substrates. In the Friedland and Silverstein method (15), ACE activity was measured in $10 \mu \mathrm{l}$ plasma with $5 \mathrm{mM}$ HipHis-Leu as substrate, in a final volume of $250 \mu$ l. In the method described here, $5 \mu$ l plasma was incubated with $10 \mu \mathrm{M} \mathrm{Abz-}$

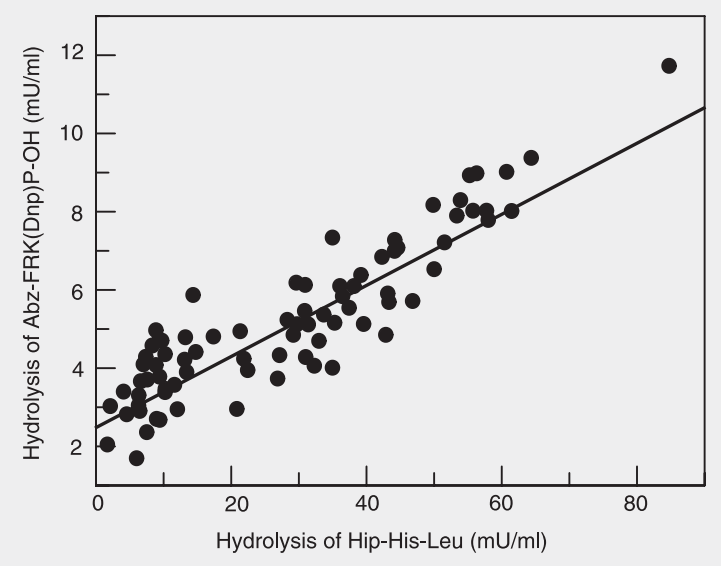

FRK(Dnp)P-OH in a final volume of $1.0 \mathrm{ml}$. Abz-FRK(Dnp)P-OH = ortho-aminobenzoic acid-FRK-(2,4-dinitrophenyl)P-OH. The correlation coefficient was $r=0.90, P<0.001$; paired Student $t$-test). The assays were performed in duplicate and differences were $<10 \%$. 
phenanthroline, indicating the interference of a metallopeptidase other than ACE (data not shown).

The sensitivity of the assay can be evaluated from the data presented in Table 2. As expected, ACE activity was much higher in the lung compared to the other tissues. However, due to the small amount of the enzyme

Table 2. Rat tissue ACE activity measurements with Abz-FRK(Dnp)P-OH and inhibition with $0.5 \mu \mathrm{M}$ lisinopril or captopril.

\begin{tabular}{lcccc} 
Substrate & \multicolumn{4}{c}{$\mathrm{mU}$ per mg of protein (inhibition, \%) } \\
\cline { 2 - 5 } & Lung & Kidney & Heart & Liver \\
\hline Abz-FRK(Dnp)P-OH & $71.2(100)$ & $1.1(100)$ & $0.4(100)$ & $0.1(58)$
\end{tabular}

Experimental conditions: the assays were performed at $37^{\circ} \mathrm{C}$ in $0.1 \mathrm{M} \mathrm{Tris-} \mathrm{HCl}, \mathrm{pH} 7.0$, containing $50 \mathrm{mM} \mathrm{NaCl}, 10 \mu \mathrm{M} \mathrm{ZnCl}_{2}, 10 \mu \mathrm{M} \mathrm{E64,} 1 \mu \mathrm{M}$ pepstatin, $1 \mathrm{mmol} / \mathrm{PMSF}, 100$ $\mu \mathrm{M}$ TLCK, and $100 \mu \mathrm{mol} / \mathrm{IPCK}$, in a final volume of $1.0 \mathrm{ml}$. Substrate: $10 \mu \mathrm{M}$. ACE = angiotensin converting enzyme; Abz-FRK(Dnp)P-OH = ortho-aminobenzoic acid-FRK(2,4-dinitrophenyl)P-OH; PMSF = phenyl-methylsulfonyl fluoride; TPCK $=\mathrm{N}$-tosyl-Lphenylalanyl-chloromethyl ketone; TLCK $=N$-tosyl-lysyl-chloromethyl ketone.

Figure 3. Effect of protein concentration on the hydrolytic activity of rat tissue homogenates on $10 \mu \mathrm{M}$ AbzFRK(Dnp)P-OH. Initial rates of hydrolysis were determined as shown in the insets. A, Lung homogenate under different concentrations; inset: continuously fluorescence recording of the hydrolysis by $0.8 \mu \mathrm{g}$ protein in absence (circles), in presence of the cocktail of inhibitors (squares) and in presence of the cocktail of inhibitors plus $0.5 \mu \mathrm{M}$ lisinopril (triangles). $B$, Kidney homogenate; inset: initial hydrolysis rate determination: $30 \mu \mathrm{g}$ protein in absence (circles) and in presence of the cocktail of inhibitors (squares) and with $0.5 \mu \mathrm{M}$ lisinopril (triangles). Abz-FRK(Dnp)P-OH = orthoaminobenzoic acid-FRK(2,4-dinitrophenyl)P-OH. Measurements were made in duplicate and differences were $<5 \%$.
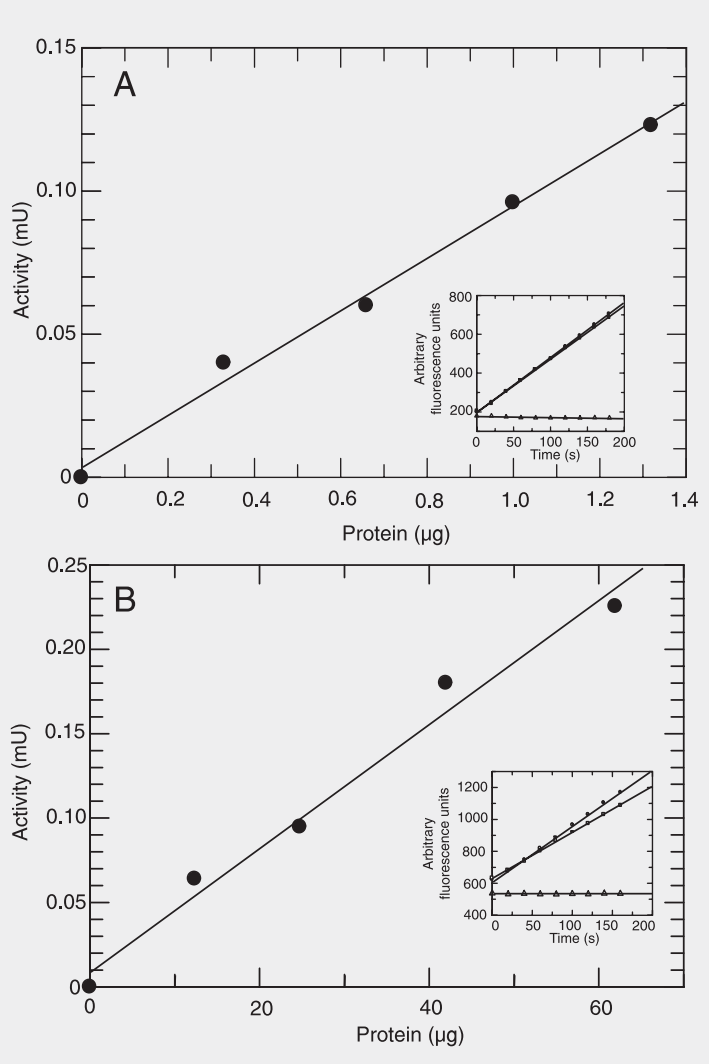

in the liver and the hydrolysis of AbzFRK(Dnp)P-OH by an enzyme different from ACE, this substrate is not convenient for ACE determinations in crude extracts of liver.

Figure 3 shows the sensitivity of AbzFRK(Dnp)P-OH for ACE activity detection at different protein concentrations of rat lung and kidney. Using this substrate, reliable ACE activity measurements can be made with as little as $0.3 \mu \mathrm{g}$ lung homogenate while $10 \mu \mathrm{g}$ kidney homogenate is needed for the enzyme measurement.

\section{Discussion}

ACE measurement in human plasma and tissues can provide essential information for the investigation of some physiological and pathophysiological situations. Colorimetric, fluorometric and radiolabeled assays have been described to monitor the enzyme activity. However, all of these methods have some limitations. We have previously described internally quenched fluorogenic bradykinin-related peptides bearing a blocked C-terminal carboxyl group (Abzpeptidyl-EDDnp) for ACE determination in purified enzyme preparations and in human plasma (22). Later, we reported the development of highly efficient fluorogenic substrates for the enzyme with the general sequence Abz-peptidyl-K(Dnp)P-OH(23). The activity of recombinant ACEs upon these peptides with a free C-terminal carboxyl group was significantly more efficient than the activity described for Abz-peptidylEDDnp analogues of bradykinin. The kinetic parameters for hydrolysis of AbzFRK(Dnp)P-OH and Abz-YRK(Dnp)P-OH by wild-type human recombinant ACE classify these peptides among the best substrates described for ACE (23). The improvement in the sensitivity of the assay and the great interest in the development of a method for ACE determinations on a continuous basis led us to standardize the assay for enzyme 
activity determinations in human plasma and crude extracts of rat tissues.

The determination of ACE activity in clinical studies is normally based on hydrolysis of Hip-His-Leu and measurement of the fluorescence of the ortho-phthaldialdehyde-His-Leu adduct (15). This technique is well established but has the limitation of being laborious, requiring seven steps. In addition, depending on the buffer used, the hydrolysis of His-Leu by dipeptidases present in plasma and tissues can underestimate ACE activity by destroying the compound that emits the fluorescence (18). The fluorometric method described here has the important advantage of being rapid and very sensitive. The assays can be performed directly in the cuvette of the fluorometer and the hydrolysis monitored by continuous recording for no more than $10 \mathrm{~min}$. Another favorable point is that the fluorescence signal appears immediately after hydrolysis, and the further hydrolysis of the products resulting from ACE activity does not interfere with the fluorescence measurements.

Human plasma ACE concentration is rather low and in some pathologies the enzyme content is decreased. The high catalytic efficiency $\left(52.6 \mu \mathrm{M}^{-1} \mathrm{~s}^{-1}\right)$ observed for the hydrolysis of Abz-FRK(Dnp)P-OH by recombinant human ACE (23) makes this peptide the most favorable substrate for determination of the enzyme in human plasma. The regression analysis presented in Figure
2 comparing ACE measurements obtained with Abz-FRK(Dnp)P-OH to the fluorometric method which uses Hip-His-Leu as substrate demonstrates that both assays correlate closely. For normal subjects, the assay can be run with $1 \mu \mathrm{l}$ human plasma in a final volume of $1 \mathrm{ml}$. The specificity for ACE measurements was demonstrated by the complete inhibition of the hydrolytic activity in the presence of $0.5 \mu \mathrm{M}$ lisinopril or captopril.

In tissue homogenates, classical inhibitors of serine, aspartyl and cysteine peptidases were used in ACE measurements with Abz-FRK(Dnp)P-OH to eliminate the interference of these enzyme classes without affecting ACE activity. However, the interference of a metallopeptidase different from ACE in the liver could not be abolished (Table 2). Therefore, despite being a very specific and efficient substrate for ACE determinations in lung, kidney and heart, the peptide Abz-FRK(Dnp)P-OH was hydrolyzed by another peptidase present in the liver.

A metallopeptidase from human liver which degrades bradykinin and atrial natriuretic peptide was purified to homogeneity by Carvalho et al. (32). Another possibility is the interference of the Thimet oligopeptidase (EC 3.4.24.15), which has been reported to be the major liver kininase in the rat (33).

\section{References}

1. Skeggs LT, Kahn JR \& Shumway NP (1956). Preparation and function of the hypertensin converting enzyme. Journal of Experimental Medicine, 103: 295-299.

2. Yang HYT, Erdös EG \& Levin Y (1970). A dipeptidyl carboxypeptidase that converts angiotensin I and inactivates bradykinin. Biochimica et Biophisica Acta, 214: 374-376.

3. Soubrier F, Alhenc-Gelas F, Hubert C, Allegrini J, John M, Tregear G \& Corvol P (1988). Two putative active centers in human angiotensin I-converting enzyme. Proceedings of the National Academy of Sciences, USA, 85: 9386-9390.

4. Bernstein KE, Martin BM, Edwards AS \& Bernstein EA (1989).
Mouse angiotensin converting enzyme is a protein composed of two homologous domains. Journal of Biological Chemistry, 264: 1194511951.

5. Lattion AL, Soubrier F, Allegrini J, Hubert C, Corvol P \& AlhencGelas F (1989). The testicular transcript of angiotensin I-converting enzyme encodes for the ancestral, non-duplicated form of the enzyme. FEBS Letters, 252: 99-104.

6. Ehlers MRW, Fox EA, Strydom DJ \& Riordan JF (1989). Molecular cloning of human testicular angiotensin-converting enzyme: the testis isoenzyme is identical to the C-terminal half of endothelial angiotensin-converting enzyme. Proceedings of the National Academy of 
Sciences, USA, 86: 7741-7745.

7. Wei L, Alhenc-Gelas F, Soubrier F, Michaud A, Corvol P \& Clauser E (1991). Expression and characterization of recombinant human angiotensin I-converting enzyme. Evidence for a C-terminal transmembrane anchor and for a proteolytic processing of the secreted recombinant and plasma enzymes. Journal of Biological Chemistry, 266: $5540-5546$.

8. Beldent V, Michaud A, Wei L, Chauvet MT \& Corvol P (1993). Proteolytic release of human angiotensin-converting enzyme. Journal of Biological Chemistry, 268: 26428-26434.

9. Cushman DW \& Cheung HS (1971). Concentration of angiotensinconverting enzyme in tissues of rat. Biochimica et Biophisica Acta, 250: 261-265.

10. Mendelsohn FAO, Allen AM, Chai SY, McKinley MJ, Oldfield BJ \& Paxinos $G$ (1990). The brain angiotensin system: insights from mapping its components. Trends in Endocrinology and Metabolism, 1: $189-197$.

11. Dzau VJ (1987). Implications of local angiotensin production in cardiovascular physiology and pharmacology. American Journal of Cardiology, 59: 59-65.

12. Dzau VJ (1988). Circulating versus local renin angiotensin system I cardiovascular homeostasis. Circulation, 77: 4-13.

13. Cushman DW \& Cheung HS (1971). Spectrophotometric assay and properties of the angiotensin-converting enzyme of rabbit lung. Biochemical Pharmacology, 20: 1637-1648.

14. Holmquist B, Bunning P \& Riordan JF (1979). A continuous spectrophotometric assay for angiotensin converting enzyme. Analytical Biochemistry, 95: 540-548.

15. Friedland J \& Silverstein E (1976). A sensitive fluorometric assay for serum angiotensin converting enzyme. American Journal of Clinical Pathology, 66: 416-424.

16. Friedland J \& Silverstein E (1977). Sensitive fluorometric assay for serum angiotensin converting enzyme with natural substrate angiotensin I. American Journal of Clinical Pathology, 68: 225-228.

17. Carmel A \& Yaron A (1978). An intramolecularly quenched fluorescent tripeptide as a fluorogenic substrate of angiotensin I-converting enzyme and a bacterial dipeptidyl carboxypeptidase. European Journal of Biochemistry, 87: 265-273.

18. Oliveira EM, Santos RAS \& Krieger JE (2000). Standardization of a fluorometric assay for the determination of tissue angiotensin-converting enzyme activity in rats. Brazilian Journal of Medical and Biological Research, 33: 755-764.

19. Meng QC, Balcells E, Dell'Italia L, Durand J \& Oparil S (1995). Sensitive method for quantitation of angiotensin-converting enzyme (ACE) activity in tissue. Biochemical Pharmacology, 50: 1490-1498.

20. Rohrabach MS (1978). (Glycine- $1{ }^{14} \mathrm{C}$ ) Hippuryl-L-histidyl-L-leucine A substrate for the radiochemical assay of angiotensin converting enzyme. Analytical Biochemistry, 84: 272-276.
21. Alhenc-Gelais F, Weare JA, Johnson RL \& Erdös EG (1983). Measurement of human converting enzyme level by direct radioimmunoassay. Journal of Laboratory and Clinical Medicine, 101: 83-95.

22. Araujo MC, Melo RL, Del Nery E, Alves MFM, Juliano MA, Casarini DE, Juliano L \& Carmona AK (1999). Internally quenched fluorogenic substrates for angiotensin I-converting enzyme. Journal of Hypertension, 17: 665-672.

23. Araujo MC, Melo RL, Cesari MH, Juliano MA, Juliano L \& Carmona AK (2000). Peptidase specificity characterization of C- and N-terminal catalytic sites of angiotensin I-converting enzyme. Biochemistry, 39: 8519-8525.

24. Juliano MA \& Juliano L (1985). Synthesis and kinetic parameters of hydrolysis by trypsin of some acyl-arginyl-p-nitroanilides and peptides containing arginyl-p-nitroanilide. Brazilian Journal of Medical and Biological Research, 18: 435-445.

25. Hirata IY, Boschcov P, Oliveira MCF, Juliano MA, Miranda A, Chagas JR, Tsuboi S, Okada Y \& Juliano L (1991). Synthesis of human angiotensinogen (1-17) containing one of the putative glycosylation binding sites and its hydrolysis by human renin and porcine pepsin. International Journal of Peptide and Protein Research, 38 : 298-307.

26. Barlos K, Gatos D, Rapolos S, Papaphotiu G, Schafer W \& Yao WQ (1989). Esterification of partially protected peptide-fragments with resins - utilization of 2-chlorotritylchloride for synthesis of Leu-15gastrin-I. Tetrahedron Letters, 30: 3947-3950.

27. Ehlers MRW \& Riordan JF (1991). Angiotensin-converting enzyme: Zinc and inhibitor binding stoichiometries of the aromatic and testis enzymes. Biochemistry, 30: 7118-7126.

28. Bradford MM (1976). A rapid and sensitive method for the quantification of microgram quantities of protein utilizing the principle of protein-dye binding. Analytical Biochemistry, 72: 248-254.

29. Leatherbarrow RJ (1992). Grafit Version 3.0. Erithacus Software Ltd., Staines, UK.

30. Colton T (1974). Statistics in Medicine. Little, Brown \& Co., Boston, MA, USA.

31. Cheung HS \& Cushman DW (1973). Inhibition of homogeneous angiotensin-converting enzyme of rabbit lung by synthetic venom peptides of Bothrops jararaca. Biochimica et Biophisica Acta, 293: 451-463.

32. Carvalho K, Nava RA, França MSF, Medeiros MAS, Camarão GC \& Juliano $L$ (1999). A liver metallopeptidase which degrades the circulating hypotensive peptide hormone bradykinin and atrial natriuretic peptide. Brazilian Journal of Medical and Biological Research, 32 51-54.

33. Molina HM, Carmona AK, Kouyoumdjian M \& Borges DR (2000). Thimet oligopeptidase EC 3.4.24.15 is a major liver kininase. Life Sciences, 67: 509-520 